\title{
The effects of concentration and heating-cooling rate on rheological properties of Plantago lanceolata seed mucilage
}

Hesarinejad, Mohammad Ali; Sami Jokandan, Maryam; Mohammadifar, Mohammad Amin; Koocheki, Arash; Razavi, Seyed Mohammad Ali; Ale, Marcel Tutor; Attar, Farnaz Rezaiyan

Published in:

International Journal of Biological Macromolecules

Link to article, DOI:

10.1016/j.ijbiomac.2017.10.102

Publication date:

2018

Document Version

Peer reviewed version

Link back to DTU Orbit

Citation (APA):

Hesarinejad, M. A., Sami Jokandan, M., Mohammadifar, M. A., Koocheki, A., Razavi, S. M. A., Ale, M. T., \& Attar, F. R. (2018). The effects of concentration and heating-cooling rate on rheological properties of Plantago lanceolata seed mucilage. International Journal of Biological Macromolecules, 115, 1260-1266.

https://doi.org/10.1016/j.ijbiomac.2017.10.102

\section{General rights}

Copyright and moral rights for the publications made accessible in the public portal are retained by the authors and/or other copyright owners and it is a condition of accessing publications that users recognise and abide by the legal requirements associated with these rights.

- Users may download and print one copy of any publication from the public portal for the purpose of private study or research.

- You may not further distribute the material or use it for any profit-making activity or commercial gain

- You may freely distribute the URL identifying the publication in the public portal 


\section{Accepted Manuscript}

Title: Dependence of concentration and heating-cooling rate on rheological properties of Plantago lanceolata seed mucilage

Authors: Mohammad Ali Hesarinejad, Maryam Sami Jokandan, Mohammad Amin Mohammadifar, Arash

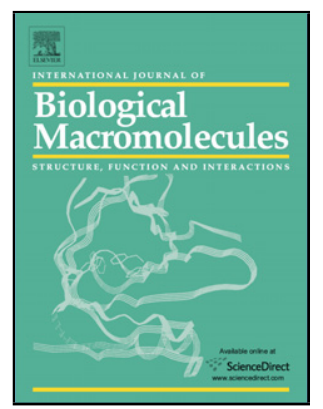

Koocheki, Seyed Mohammad Ali Razavi, Marcel Tutor Ale, Farnaz Rezaiyan Attar

PII:

S0141-8130(17)32014-7

DOI: https://doi.org/10.1016/j.ijbiomac.2017.10.102

Reference: BIOMAC 8397

To appear in: International Journal of Biological Macromolecules

Received date:

5-6-2017

Revised date: 30-9-2017

Accepted date: $16-10-2017$

Please cite this article as: Mohammad Ali Hesarinejad, Maryam Sami Jokandan, Mohammad Amin Mohammadifar, Arash Koocheki, Seyed Mohammad Ali Razavi, Marcel Tutor Ale, Farnaz Rezaiyan Attar, Dependence of concentration and heating-cooling rate on rheological properties of Plantago lanceolata seed mucilage, International Journal of Biological Macromolecules https://doi.org/10.1016/j.ijbiomac.2017.10.102

This is a PDF file of an unedited manuscript that has been accepted for publication. As a service to our customers we are providing this early version of the manuscript. The manuscript will undergo copyediting, typesetting, and review of the resulting proof before it is published in its final form. Please note that during the production process errors may be discovered which could affect the content, and all legal disclaimers that apply to the journal pertain. 


\title{
Dependence of concentration and heating-cooling rate on rheological properties of Plantago lanceolata seed mucilage
}

Mohammad Ali Hesarinejad ${ }^{1,2, *}$, Maryam Sami Jokandan³, Mohammad Amin Mohammadifar², Arash Koocheki $^{1}$, Seyed Mohammad Ali Razavi ${ }^{1}$, Marcel Tutor Ale ${ }^{4}$, Farnaz Rezaiyan Attar ${ }^{1}$

\footnotetext{
${ }^{1}$ Department of Food Science and Technology, Ferdowsi University of Mashhad (FUM), PO Box 91775-1163, Mashhad, Iran

${ }^{2}$ Research Group for Food Production Engineering, National Food Institute, Technical University of Denmark, Søltofts Plads, 2800, Kgs. Lyngby, Denmark

${ }^{3}$ Research Group for Nano-Bio Science, National Food Institute, Technical University of Denmark, Søltofts Plads, 2800, Kgs. Lyngby, Denmark

${ }^{4}$ Department of Chemical and Biochemical Engineering, Technical University of Denmark, Søltofts Plads, 2800, Kgs. Lyngby, Denmark
}

\begin{abstract}
In this study, the effect of concentration $(0.5,1,1.5$ and $2 \%)$ and heating-cooling rate $(1,5$ and $10{ }^{\circ} \mathrm{C} \cdot \mathrm{min}^{-1}$ ) on the rheological properties of Plantago lanceolata seed mucilage (PLSM) solutions were investigated. It was observed that the gum dispersions exhibited viscoelastic properties under the given conditions. Mechanical spectra of PLSM were classified as weak gels based on the frequency sweep, complex viscosity $(\eta *)$ and $\tan \delta$ results. All variables had significant impacts on the rheological parameters. Chemical and monosaccharide compositions were also determined to provide more structural information. The results revealed that PLSM had high total sugar content $(87.35 \%)$, and it is likely an arabinoxylomannan-type polysaccharide.
\end{abstract}

Keywords: Plantago lanceolata seed mucilage; Rheology; Sugar composition.

\section{Introduction}

Hydrocolloids, also called gums, are macromolecules that dissolve or disperse in water and form viscous dispersions or gels [1]. Hydrocolloids play a great role in food and pharmaceutical industries due to their wide array of functions including; thickening, gel forming, texture producing, emulsifying, stabilizing, controlling crystallization and preventing syneresis [2]. The most important hydrocolloids in food systems are pectin, 
galactomannans, carrageenan, alginate, agar, Arabic gum, starch and cellulose and their derivatives [3].

These polymers have the advantage of being considered as totally natural for many consumers [4]. Selection of a suitable hydrocolloid for a system depends on hydrocolloid's functions and desirable properties in foods [5], aside from their costs and safety [6]. The annual use of hydrocolloids is constantly increasing and consequently recent efforts have been focused on finding new sources of more efficient and economic hydrocolloids.

The rheological behavior of hydrocolloids is of special importance when they are used for modifying textural attributes. It is also well-recognized that rheological properties play a vital role in process design, evaluation and modeling and are considered as measurement for product quality (e.g. indication of total solids or change in molecular size). Rheological data is required for calculation in any processes involving fluid flow (e.g. pump sizing, extraction, filtration, extrusion, purification) and plays an important role in the analyses of flow conditions in food processes such as pasteurization, evaporation, drying and aseptic processing [7].

Dynamic and steady shear rheological properties can be used to provide insight on the structural properties of a sample [8]. Small-amplitude oscillatory shear (SAOS) measurements are a type of dynamic rheological test in which, stress and strain are varied harmonically with time in the linear viscoelastic region (LVR). Expanding the database on the viscoelastic properties of gum solutions/dispersions is critical in food processing in order to adjust processing parameters, monitor consistency as well as predicting the stability of fluid food systems and the final textural attributes of formulated food. Therefore, dynamic rheology is one of the methods used most extensively to assess the viscoelastic behavior of polysaccharide solutions/dispersions or gels. The viscoelastic properties of various gums such as xanthan, guar [9], pectin [10], Opuntia ficus indica mucilage [11], basil seed gum [12], gum tragacanth [13], Lepidium perfoliatum seed gum [14] and Alyssum homolocarpum seed gum [1] have been reported by other researchers.

Generally, the rheological properties of hydrocolloid solutions are influenced by many parameters such as concentration of the active compound, temperature, degree of dispersion, dissolution, electrical charge, previous thermal and mechanical treatment, presence or absence of other lyophilic colloids, the presence of electrolytes and non-electrolytes, $\mathrm{pH}$, ionic strength and salts $[3,15]$. 
Plantago, of the plantaginaceae family, is one of the most plentiful and widely distributed medicinal plants throughout the world. Plantago lanceolata L., also known as Ribwort or Ribwort Plantain [16,17], produces large amounts of seeds. These seeds have for a long time been used as an anti-catarrhal, respiratory demulcent [16], subtle antibiotic, cough and bronchitis remedies [18]. Plantago lanceolata seed mucilage (PLSM) is extracted predominantly from the outermost layer of the seed hull. The hull release mucilaginous substance when immersed in water. Accordingly, aqueous extraction is one of the most popular techniques used for the extraction of seed mucilage. The rheological properties of PLSM are of high interest in world due to its widespread usage in the traditional pharmaceutical prescriptions [19].

As a result of diversity in different gum structures and extrinsic conditions within the fluid food systems, the rheological behaviors are different from one gum solution to another [14]. Hence, food companies may have a hard time deciding which gums to use in their fluid food formulations. Thus, an understanding of the rheological properties of PLSM is essential for evaluating its potential applications and use as food thickeners or stabilizers.

However, despite the great potential of temperature impact on rheological properties of this rarely investigated hydrocolloid, no extensive research has been performed on the rheological properties of PLSM when commonly used thermal processes. There is no published information about the viscoelastic behaviour of this mucilage. In this study, the objectives were to investigate dynamic rheological properties of PLSM and its dependency to concentration and temperature. The effect of consecutive heating-cooling cycles on the viscoelasticity was also determined.

\section{Materials and methods}

\subsection{Materials}

$P$. lanceolata seeds were supplied by the local market in Mashhad, Iran. The cleaned $P$. lanceolata seeds were wrapped in plastic bags, sealed and kept in dry and cool place. All chemicals used were of analytical grade.

\subsection{Mucilage extraction}

Husks of seeds were dispersed in distilled water at a water/husk ratio of 20:1. The husk-water slurry was stirred continuously with a mechanical mixing paddle throughout the entire extraction period $(1 \mathrm{~h})$. Husks of $P$. lanceolata seeds were separated from the seed coats by 
mechanical milling of the outer layer of the seeds using a $27-\mathrm{cm}$ basket centrifuge lined with a 1-mm mesh. The seeds were discarded and ultimately, the dispersion was dried in a conventional oven (overnight at $45{ }^{\circ} \mathrm{C}$ ), milled and sieved using a mesh 18 sifter [20]. The powder was stored in an air-tight test tube at room temperature for further experiments.

\subsection{Chemical analysis}

In order to determine moisture, fat, ash and protein contents of PLSM samples, AOAC method was used [21]. The protein content was quantified using nitrogen to protein conversation factor of 6.25. Total carbohydrate content was subtracted from $100 \%$ (Moisture + Ash + Fat + Protein).

The monosaccharide analysis was performed by NREL two-step acid hydrolysis and quantified using HPAEC-PAD. In brief, ca. $30 \mathrm{mg}$ dry matter PLSM material was mixed with $72 \% \mathrm{H}_{2} \mathrm{SO}_{4}$ and left for $1 \mathrm{~h}$ to react at $30{ }^{\circ} \mathrm{C}$. The reaction mixture was then diluted to $4 \%$ $\mathrm{H}_{2} \mathrm{SO}_{4}$ and hydrolyzed in an autoclave at $120{ }^{\circ} \mathrm{C}$ for $40 \mathrm{~min}$. [22]. HPAEC separation of the PLSM was performed using a HPAEC-PAD, ICS5000 system (Dionex Corp. Sunnyvale, CA) equipped with a CarboPac ${ }^{\mathrm{TM}}$ PA1 column by a method principally as described by Arnous and Meyer [23]. L-arabinose, L-rhamnose, D-galactose, D-glucose, D-xylose, Dmannose, D-galacturonic acid, and D-glucuronic acid were used as monosaccharide standards for quantification, which was performed using Chromeleon software (Dionex Corp. Sunnyvale, CA). Recovery values for the monosaccharides were estimated from parallel runs of monosaccharide standards.

\subsection{Samples preparation}

After preparing dried mucilage, aqueous dispersions of PLSM were prepared at different concentrations $(0.5,1,1.5$ and $2 \% \mathrm{w} / \mathrm{v})$ in deionized water. Different concentrations of $\mathrm{NaCl}$ and $\mathrm{CaCl}_{2}(50,100,500$ and $1000 \mathrm{mM})$ were added separately at every concentration of PLSM while stirring for $30 \mathrm{~min}$. Finally, $10 \mathrm{ml}$ of dispersions were stirred by roller shaker for $24 \mathrm{~h}$ at room temperature; and left at $4^{\circ} \mathrm{C}$ overnight to ensure a complete hydration prior to use in oscillation tests.

\subsection{Small amplitude oscillatory shear measurements}

Dynamic rheological measurements were conducted using HAAKE MARS III rheometer (Thermo Scientific, Karlsruhe, Germany) equipped with a Peltier plate for temperature control. A "parallel plate sensor" PP35/1Ti (diameter of $35 \mathrm{~mm}$ ) was used for measurements. 
Each sample was transferred onto the rheometer plate at the ambient temperature and excess material was wiped off with a spatula. In order to relax the samples before measurements, they were allowed to rest at the initial temperatures for $1 \mathrm{~min}$. The RheoWin software 3.61 (Thermo Fisher Scientific) was employed for data evaluation. At least duplicate of each measurement were made.

Prior to making detailed dynamic measurements to examine the sample's microstructure, the linear viscoelastic region (LVR) must first be defined. The linear viscoelastic region (LVR) for PLSM samples was determined by performing an amplitude sweep measurements (0.01$100 \%)$ at constant frequency $(1 \mathrm{~Hz})$ and temperature $\left(25^{\circ} \mathrm{C}\right)$.

Frequency sweep tests at a constant strain in the LVE region were carried out to determine the viscoelastic nature of PLSM. In this test a strain of only $0.2 \%$ was applied in order to disturb the network formation the minimum possible. The mechanical spectra were characterized by $G^{\prime}$ and $G^{\prime \prime}[\mathrm{Pa}]$ as functions of frequency in the range of $0.01-10 \mathrm{~Hz}$ at $25^{\circ} \mathrm{C}$. The storage and loss modulus account for the elastic and viscous component of a sample, respectively.

The temperature sweep measurements were performed at the constant strain of $0.2 \%$, which was well within the linear viscoelastic region, while the frequency was fixed at $1.0 \mathrm{~Hz}$.

The effect of temperature on rheological properties of PLSM was studied in four steps as follow; (a) linear increase in temperature from $20^{\circ} \mathrm{C}$ to $90^{\circ} \mathrm{C}$ (heating), (b) keeping at $90^{\circ} \mathrm{C}$ for $10 \mathrm{~min}$, (c) linearly cooling down to $20^{\circ} \mathrm{C}$ (cooling) and (d) keeping at $20^{\circ} \mathrm{C}$ for $10 \mathrm{~min}$. The heating and cooling steps were performed at three different heating rates of 1,5 and $10^{\circ} \mathrm{C} / \mathrm{min}$,

\subsection{Statistical analysis}

Rheological properties of hydrocolloid solutions were determined by applying linear regression method based on minimizing sum of squares in Excel Microsoft Office software (v.2013). Model equations and regression coefficients $\left(\mathrm{R}^{2}\right)$ were reported and Analysis of variance (ANOVA) was applied to acknowledge any significant difference among rheological parameters; $\mathrm{n}$ and $\mathrm{k}$ at $\mathrm{P}<0.05$. The SPSS (version 13.0) program was used for all statistical analysis. All experiments were replicated minimum three times. 


\section{Results and discussion}

\subsection{Chemical composition}

Chemical analysis indicated that the mucilage contained $4.01 \%$ protein, $3.17 \%$ moisture, $5.47 \%$ ash and no fat content. The values of ash and moisture contents were lower than the ones reported by Koocheki et al. [24] for Eruca sativa seed mucilage, Hosseini-Parvar et al. [25] for Ocimum basilicum L. seed mucilage and by Razavi et al. [26] for Basil seed gum. However, the protein and carbohydrate content observed was higher than Ocimum basilicum L. seed mucilage and Basil seed gum.

The total sugar content was $87.35 \%$. PLSM samples comprise small amount of uronic acids (7.45\%), revealing its weak polyelectrolyte nature and the relative amount of acidic polysaccharides in the mucilage. The uronic acid content of PLSM was higher than that of A.homolocarpum seed gum (5.63\%) [1]. However, it was lower than that of gum Arabic (15.0\%), xanthan gum (21.9\%), flaxseed gum (21.0-25.1\%), C.pareira pectin (70.56\%), cress seed gum (15\%), gum ghatti (12.83\%), A.bracteatum gum (10.3\%), sage seed gum (28.2$32.2 \%$ ), and Plantago major seed mucilage (8.19\%) [3,27-32].

\subsection{Strain sweep measurements}

In strain sweep measurements with raising stain, the two different domains namely linear viscoelastic and nonlinear regions were eminent. In the linear viscoelastic region, $\mathrm{G}^{\prime}$ and $\mathrm{G}^{\prime \prime}$ were nearly stable and in the nonlinear region, $G^{\prime}$ and $G^{\prime \prime}$ started to diminish. In the strain sweep measurements, $\mathrm{G}^{\prime}$ remained constant until the strain reached a critical point at which $\mathrm{G}^{\prime}$ began to decrease sharply (Fig.1). The strain at which $\mathrm{G}^{\prime}$ decrease precipitously is called the critical strain. Therefore, critical strain reflects the deformability of the mucilage.

Strong gum solutions remain longer at linear state compared to weak gum solutions [33]; since the gum employed in this study is a strong gum, its viscoelastic moduli can be linear in a wide range of strain amplitudes. The linear region decrease respectively from gels to concentrated solutions and dilute solutions. While the strain value at the limit of LVR rarely exceeds $0.1 \%$ for colloidal gels, it may become equal to or above $1 \%$ for natural biopolymer gels [8]. 
The limiting values of strain $\left(\gamma_{\mathrm{L}}\right)$, tan $\delta$ and $\tau$ obtained within the LVR ranges are tabulated in Table 1. At low mucilage concentrations $(0.5-1 \%)$, the elastic modulus remained constant up to ca. $1 \%$ strain. With increasing mucilage concentration, the strain at which the elastic modulus decreased, increased to more than $1 \%$ (Table 1). This indicates that increasing mucilage concentration, would increase the strength of the system and make it more rigid. The limiting value of strain $\left(\gamma_{\mathrm{L}}\right)$ was high for $2 \%$ PLSM, implying a higher stability of the viscoelastic material under the $\gamma$-amplitude. Therefore, the strain of $0.2 \%$ for frequency sweep tests were well within the LVR, where the weak gel network was not damaged by the strain imposed during the measurements.

The values of $\mathrm{G}^{\prime}$ and $\mathrm{G}^{\prime \prime}$ at LVR also increased with increase in mucilage concentrations (Table 1). This type of test also determines the maximum deformation that a system can withstand before structural failure; in other words, determination of the critical strain within as corresponding of the LVR is a criterion of structural strength and shape retention versus the mechanical stresses. The stress corresponding to this strain is considered as yield stress (the tension that led to the first non-linear changes in the structure) [14].

Increasing mucilage concentration raise the yield stress values at flow point, meaning that the gel network became stronger (Table 1). The yield stress values for PLSM were 4.84, 5.53, 19.20 and $22.90 \mathrm{~Pa}$ for $0.5 \%, 1 \%, 1.5 \%$ and $2 \%$ mucilage concentrations, respectively. Yield stress has been considered as useful property of mucilage when they are used as binders, because it helps to cohere the different components of food formulations [34]. However, the magnitude of yield stress depends on the measuring technique and it is reported that yield stress values are actually defined by the rheological techniques and the assumptions made during the measurements $[33,35]$. The magnitudes of the viscoelastic moduli for PLSM were similar to previously reported values for some other food hydrocolloids such as Alyssum homolocarpum seed gum [1], Lepidium perfoliatum seed gum [14], maize starch pastes [36] and rice starch galactomannan mixtures [37].

\subsection{Frequency sweep measurements}

Frequency sweep information can be used to characterize or classify dispersions. The four most common and traditional classifications of dispersions are dilute solution, entanglement network systems (or a concentrated solution), weak gel and strong gel [8,33]. Fig. 2 shows 
the changes in storage modulus $\left(\mathrm{G}^{\prime}\right)$ and loss modulus $\left(\mathrm{G}^{\prime \prime}\right)$ as a function of frequency $(\mathrm{Hz})$ and concentration at $25^{\circ} \mathrm{C}$. The PLSM had typical week-gel like behavior where the magnitudes of $G^{\prime}$ and $G^{\prime \prime}$ slightly increased with raising frequency, having limited frequency dependency. According to Martínez-Ruvalcaba, Chornet, and Rodrigue [38], in week gels, both moduli show slight frequency dependency, with $\mathrm{G}^{\prime}$ exceeding $\mathrm{G}^{\prime \prime}$ at all frequencies. The storage modulus $\left(G^{\prime}\right)$ for PLSM was always higher than loss modulus $\left(G^{\prime \prime}\right)$ within the experimental range of frequencies $(0.01-10 \mathrm{~Hz})$ and no crossover point occurred. Therefore, PLSM behaves more like a solid; that is, the deformations are elastic and recoverable. This behavior is compatible with that found in other hydrocolloids such as psyllium [39,40], rice starch-xanthan gum [41], basil seed gum [12], Lepidium perfoliatum seed gum [14] and Alyssum homolocarpum seed gum [1]. An increase in both storage and loss moduli were observed when concentration increased (Fig. 2), which is due to development of complex structures as concentration rises. The escalation in $\mathrm{G}^{\prime}$ and $\mathrm{G}^{\prime \prime}$

while being parallel, is connected with network defects [42]. In other words, at low concentrations, there are many intermolecular zones that do not participate in non-covalence cross junctions [42-44], while at high concentrations (1.5-2\%), the maximum number of junction zones are formed. On the other hand, with increasing PLSM concentration, $\mathrm{G}^{\prime}$ becomes greater than $\mathrm{G}^{\prime \prime}$ indicating a clear tendency to form macromolecular networks. This type of behavior has also been reported by other authors for $\kappa$-carrageenan gels $[45,46]$, gellan gum gels [47,48], $\kappa$-carrageenan/LBG gels [49,50], psyllium gels [40], Lepidium perfoliatum seed gum [14] and Alyssum homolocarpum seed gum[1].

Another characteristic value for evaluation of the viscoelastic behavior of mucilage is loss tangent $(\tan \delta)$ which is the ratio of $\mathrm{G}^{\prime \prime} / \mathrm{G}^{\prime}$. Tan $\delta$ is directly related to the energy lost per cycle divided by the energy stored per cycle. A $\tan \delta<1$ indicates predominantly elastic behavior while $\tan \delta>1$ indicates predominantly viscous behavior. In polymer systems, large $\tan \delta$ is an indication of dilute solutions while values between 0.2-0.3 reveal amorphous polymers and finally small $\tan \delta$ (near 0.01 ) suggest glassy crystalline polymers and gels [33]. Within the experimental frequency range $\left(0.0628-62.8 \mathrm{rad}_{\mathrm{s}} \mathrm{s}^{-1}\right)$, the $\tan \delta$ values for samples of high concentration were between 0.18 and 0.25 which were much lower than those for low PLSM dispersions (Data not shown). This reveals that high concentration 
samples may display an intermediate behavior between a weak and an elastic gel [51]. This result is similar to that obtained for other gums such as psyllium [40], Lepidium perfoliatum seed gum [14] and Alyssum homolocarpum seed gum [1].

PLSM showed a shear dependent flow behavior as the complex dynamic viscosity $\left(\eta^{*}\right)$ decreased linearly with increasing frequency on a double logarithmic scale (Fig. 3). Therefore, we can conclude that mucilage dispersions had non-Newtonian shear-thinning behavior. Such behavior is consistent with those found for other dispersions [36,41,52-54]. The complex viscosity escalated as the mucilage concentration raised from 0.5 to $2 \%$ (Fig. 3). These results confirm the high potential of this hydrocolloid as a good thickener or stabilizer in increasing the consistency of food systems. Maskan and Gogus [55] also concluded that higher solid contents generally led to an increase in the viscosity due to the molecular movements and interfacial film formation.

From a structure point of view, for true gels, $\log \mathrm{G}^{\prime}$ versus $\log \omega$ plots have zero slope, while for weak gels and highly concentrated dispersions such plots have positive slopes and $\mathrm{G}^{\prime}$ has a higher magnitude than $\mathrm{G}^{\prime \prime}[8,56]$. Based on polymer dynamics theory, for liquid-like fluids, the frequency dependency of $G^{\prime}$ values shows a power law relation [57]. Therefore, the power-law parameters used to model the frequency dependency of $\mathrm{G}^{\prime}$ was evaluated using the following equation:

$\mathrm{G}^{\prime}=\mathrm{a} \cdot \omega^{\mathrm{b}}$

where $\mathrm{G}^{\prime}$ is the storage modulus, $\omega$ is the oscillation frequency, and $a$ is a constant. The exponent $b$ is the slope in a $\log -\log$ plot of $\mathrm{G}^{\prime}$ versus $\omega$. For a covalent gel, $b=0$ whereas for a physical gel $b>0$. Low $b$ values are characteristics of elastic gels, while for $b$ values near 1 , the system behaves as a viscous gel. At $b$ values close to zero, $\mathrm{G}^{\prime}$ does not change with frequency. The concentration significantly influenced the dynamic shear properties of the dispersions (Table 2). The frequency dependency of $\mathrm{G}^{\prime}$ decreased when PLSM concentration increased. It is known that $b$ value is related to the strength and nature of the gel [58]. This value also increased with increase in concentrations, which can be attributed to the formation of stronger network. Trckova, Stetina, and Kansky [59] also found that the elasticity of carrageenan-casein gels rose linearly with increasing carrageenan concentration. 


\subsection{Temperature sweep measurement}

The temperature at which a biopolymer melts is defined as the temperature where the dynamic shear storage modulus $\left(G^{\prime}\right)$ equals the dynamic shear loss modulus $\left(G^{\prime \prime}\right)$ (the gel-sol transition)[60]. This can be easily measured using a controlled stress rheometer in oscillatory mode. It is important to recognize that viscoelastic moduli are frequency dependent and this dependence must be recognized when measuring the melting and gelling points [60]. The effect of temperature on $G^{\prime}$ and $G^{\prime \prime}$ of PLSM at different concentrations is shown in Fig. 4. The PLSM showed a storage modulus higher than the loss modulus, in the whole range of investigated temperatures. There was no crossover point for $G^{\prime}$ and $G^{\prime \prime}$, which means the mucilage dispersion behavior was predominantly elastic and remains in the solid-like state.

During the initial heating (from 40 to $50{ }^{\circ} \mathrm{C}$ ), $G^{\prime}$ decreased slowly as temperature increased, reaching a minimum around $50{ }^{\circ} \mathrm{C}$ (Fig. 4). The initial decrease in $G^{\prime}$ can be related to fluidity increase resulting from temperature raise. It may also be attributed to the energy dissipation from molecule movements and decrease in intermolecular interactions. This in turn reduce the energy required for flow, thus lowering the interference of the hydrodynamic domains $[61,62]$.

The escalation of $G^{\prime}$ was observed to depend on PLSM concentration. With raising the temperature from 50 to $90{ }^{\circ} \mathrm{C}$, the storage and loss moduli increased uniformly (Fig. 4). The $G^{\prime}$ increase might be due to formation of three-dimensional network structures and conversion of sol fraction into gel. In the PLSM dispersions, the $G^{\prime}$ increase while heating may also be caused by the thickening effect of the gums which restricts fluid mobility. Keeping the samples at $90{ }^{\circ} \mathrm{C}$ resulted in dramatic diminish of $G^{\prime \prime}$ and slight increase in $G^{\prime}$, which suggests the presence of hydrophobic interactions. These interactions get robust by heating resulting in stronger interaction among PLSM polysaccharides molecules.

From rheological measurements of PLSM solutions, the hystereses between heating and cooling curves were found (Fig. 4). The storage modulus of PLSM decreased during cooling, which indicates that the hydrogen bonds were breaking and the network were getting weaker. However, Rafe and Razavi [12] and Hesarinejad et al [1] concluded that this increase in $G^{\prime}$ 
during cooling was due to strengthened hydrophobic interactions and hydrogen bonds, respectively. Keeping temperature at $20^{\circ} \mathrm{C}$ had no significant effect on the storage and loss moduli. The hysteresis in the rheological measurements between the heating and cooling curves decreased by decreasing heating-cooling rates, indicating that the molecules of PLSM had enough time to form hydrogen bonds and to develop a firm and thermally irreversible network (Fig. 5).

\section{Conclusion}

The dynamic flow properties of PLSM within the linear viscoelastic region were investigated as function of mucilage concentration, temperature and heating-cooling rate. Aqueous dispersions of PLSM at different concentrations $(0.5-2 \% \mathrm{w} / \mathrm{v})$ showed similar viscoelastic behaviors. Both of the fluid-like $\left(\mathrm{G}^{\prime \prime}\right)$ and solid-like $\left(\mathrm{G}^{\prime}\right)$ behaviors were observed to be dependent on concentration and temperature. The elastic component of PLSM was consistently higher than its viscous component revealing its weak-gel like properties. It was further discovered/observed that the viscoelastic moduli of PLSM is only slightly dependent on frequency indicating that it is a cross-link network. From the rheological measurements, the hysteresis between the heating and cooling curves declined by decreasing heating and cooling rates, which shows that PLSM molecules had enough time to form hydrogen bonds and develop firm and thermally irreversible networks. The results revealed that PLSM had high total sugar content (87.35\%), and it is likely an arabinoxylomannan-type polysaccharide. The monosaccharides composition demonstrated that PLSM is not a galactomannan or glucomannan. In conclusion, PLSM was stated to be an arabinoxylomannan-type polysaccharide with some compositional differences with many other seed gums. HPAEC analysis showed the presence of $69.42 \%$ Mannose as a main body with $11.98 \%$ and $7.42 \%$ Arabinose and Xylose, respectively as the main branches. Moreover, PLSM samples included a small portion of Glucuronic acids (7.45\%), featuring its weak polyelectrolyte nature and the relatively moderate amount of acidic polysaccharides in the gum. These results argue the potential use of PLSM as a replacement for some of the plant hydrocolloids used in food industry at the moment. 


\section{References}

[1] M.A. Hesarinejad, S.M.A. Razavi, A. Koocheki, Alyssum homolocarpum seed gum: Dilute solution and some physicochemical properties, Int. J. Biol. Macromol. 81 (2015) 418-426.

[2] H. Sahin, F. Ozdemir, Effect of some hydrocolloids on the rheological properties of different formulated ketchups, Food Hydrocoll. 18 (2004) 1015-1022.

[3] H. Karazhiyan, S.M.A. Razavi, G.O. Phillips, Y. Fang, S. Al-Assaf, K. Nishinari, R. Farhoosh, Rheological properties of Lepidium sativum seed extract as a function of concentration, temperature and time, Food Hydrocoll. 23 (2009) 2062-2068.

[4] L.S. Lai, J. Tung, P.S. Lin, Solution properties of hsian-tsao (Mesona procumbens Hemsl) leaf gum, Food Hydrocoll. 14 (2000) 287-294.

[5] L.N. Sadar, Rheological and textural characteristics of copolymerized hydrocolloidal solutions containing curdlan gum, (2004).

[6] B. Vardhanabhuti, S. Ikeda, Isolation and characterization of hydrocolloids from monoi (Cissampelos pareira) leaves, Food Hydrocoll. 20 (2006) 885-891.

[7] M. Marcotte, A.R. Taherian, H.S. Ramaswamy, Rheological properties of selected hydrocolloids as a, (2001).

[8] A.H. Clark, S.B. Ross-Murphy, Structural and mechanical properties of biopolymer gels, in: Biopolymers, Springer, 1987: pp. 57-192.

[9] P.L. MILLS, J.L. KOKINI, Comparison of steady shear and dynamic viscoelastic properties of guar and karaya gums, J. Food Sci. 49 (1984) 1-4.

[10] J. Gigli, C. Garnier, L. Piazza, Rheological behaviour of low-methoxyl pectin gels over an extended frequency window, Food Hydrocoll. 23 (2009) 1406-1412.

[11] L. Medina-Torres, E. Brito-De La Fuente, B. Torrestiana-Sanchez, R. Katthain, Rheological properties of the mucilage gum (Opuntia ficus indica), Food Hydrocoll. 14 (2000) 417-424.

[12] A. Rafe, S. Razavi, Dynamic viscoelastic study on the gelation of basil seed gum, Int. J. Food Sci. Technol. 48 (2013) 556-563.

[13] S. Balaghi, M.A. Mohammadifar, A. Zargaraan, H.A. Gavlighi, M. Mohammadi, Compositional analysis and rheological characterization of gum tragacanth exudates from six species of Iranian Astragalus, Food Hydrocoll. 25 (2011) 1775-1784.

[14] M.A. Hesarinejad, A. Koocheki, S.M.A. Razavi, Dynamic rheological properties of Lepidium perfoliatum seed gum: Effect of concentration, temperature and heating/cooling rate, Food Hydrocoll. 35 (2014) 583-589.

[15] M.A. Rao, R.C. Anantheswaran, Rheology of fluids in food-processing, Food Technol. 36 (1982) 116126.

[16] K. Bone, S. Mills, Principles and practice of phytotherapy: modern herbal medicine, Elsevier Health Sciences, 2013

[17] F. David Hoffmann, Medical herbalism: the science and practice of herbal medicine, Inner Traditions/Bear \& Co, 2003.

[18] J.R. Weiss, Vocal health in the choral rehearsal: Common ground for operatically trained singers, studio voice teachers and choral conductors, (2001).

[19] G.H. Amin, Medicinal plants of Iran(p. 106), Tehran, Iran Tehran Univ. Publ. (2005).

[20] L.S. Sciarini, F. Maldonado, P.D. Ribotta, G.T. Pérez, A.E. León, Chemical composition and functional properties of Gleditsia triacanthos gum, Food Hydrocoll. 23 (2009) 306-313.

[21] D. Firestone, Official Methods of Analysis, AOAC. 41 (1990) 951-986.

[22] N. Rhein-Knudsen, M.T. Ale, F. Ajalloueian, A.S. Meyer, Characterization of alginates from Ghanaian brown seaweeds: Sargassum spp. and Padina spp., Food Hydrocoll. (2017).

[23] A. Arnous, A.S. Meyer, Quantitative prediction of cell wall polysaccharide composition in grape (Vitis vinifera L.) and apple (Malus domestica) skins from acid hydrolysis monosaccharide profiles, J. Agric. Food Chem. 57 (2009) 3611-3619.

[24] A. Koocheki, S.M.A. Razavi, M.A. Hesarinejad, Effect of extraction procedures on functional properties of Eruca sativa Seed Mucilage, Food Biophys. 7 (2012) 84-92.

[25] S.H. Hosseini-Parvar, L. Matia-Merino, K.K.T. Goh, S.M.A. Razavi, S.A. Mortazavi, Steady shear flow behavior of gum extracted from Ocimum basilicum L. seed: Effect of concentration and temperature, J. Food Eng. 101 (2010) 236-243.

[26] S. Razavi, S.A. Mortazavi, L. Matia-Merino, S.H. Hosseini-Parvar, A. Motamedzadegan, E. Khanipour, 
Optimisation study of gum extraction from Basil seeds (Ocimum basilicum L.), Int. J. Food Sci. Technol. 44 (2009) 1755-1762.

[27] W. Cui, G. Mazza, Physicochemical characteristics of flaxseed gum, Food Res. Int. 29 (1996) 397-402.

[28] K. Jahanbin, S. Moini, A.R. Gohari, Z. Emam-Djomeh, P. Masi, Isolation, purification and characterization of a new gum from Acanthophyllum bracteatum roots, Food Hydrocoll. 27 (2012) 1421.

[29] J. Kang, S.W. Cui, J. Chen, G.O. Phillips, Y. Wu, Q. Wang, New studies on gum ghatti (Anogeissus latifolia) part I. Fractionation, chemical and physical characterization of the gum, Food Hydrocoll. 25 (2011) 1984-1990.

[30] S.M.A. Razavi, S.W. Cui, Q. Guo, H. Ding, Some physicochemical properties of sage (Salvia macrosiphon) seed gum, Food Hydrocoll. 35 (2014) 453-462.

[31] J. Singthong, S. Ningsanond, S.W. Cui, H.D. Goff, Extraction and physicochemical characterization of Krueo Ma Noy pectin, Food Hydrocoll. 19 (2005) 793-801.

[32] B.A. Behbahani, F.T. Yazdi, F. Shahidi, M.A. Hesarinejad, S.A. Mortazavi, M. Mohebbi, Plantago major seed mucilage: Optimization of extraction and some physicochemical and rheological aspects, Carbohydr. Polym. 155 (2017) 68-77.

[33] J.F. Steffe, Rheological methods in food process engineering, Freeman press, 1996.

[34] M.A. Rao, J.F. Kenny, Flow properties of selected food gums, Can. Inst. Food Sci. Technol. J. 8 (1975) 142-148.

[35] D.D. Christianson, E.B. Bagley, Yield stresses in dispersions of swollen, deformable cornstarch granules, Cereal Chem. 61 (1984) 500-503.

[36] M. Alloncle, J.-L. Doublier, Viscoelastic properties of maize starch/hydrocolloid pastes and gels, Food Hydrocoll. 5 (1991) 455-467.

[37] C. Kim, S. Lee, B. Yoo, Dynamic Rheology of Rice Starch-Galactomannan Mixtures in the Aging Process, Starch-Stärke. 58 (2006) 35-43.

[38] A. Martínez-Ruvalcaba, E. Chornet, D. Rodrigue, Viscoelastic properties of dispersed chitosan/xanthan hydrogels, Carbohydr. Polym. 67 (2007) 586-595.

[39] Q. Guo, S.W. Cui, Q. Wang, J.C. Young, Fractionation and physicochemical characterization of psyllium gum, Carbohydr. Polym. 73 (2008) 35-43.

[40] A. Farahnaky, H. Askari, M. Majzoobi, G. Mesbahi, The impact of concentration, temperature and $\mathrm{pH}$ on dynamic rheology of psyllium gels, J. Food Eng. 100 (2010) 294-301.

[41] C. Kim, B. Yoo, Rheological properties of rice starch-xanthan gum mixtures, J. Food Eng. 75 (2006) 120-128.

[42] S.B. Ross-Murphy, Rheological methods, in: Phys. Tech. Study Food Biopolym., Springer, 1994: pp. 343392.

[43] F. Rincón, J. Muñoz, G.L. De Pinto, M.C. Alfaro, N. Calero, Rheological properties of Cedrela odorata gum exudate aqueous dispersions, Food Hydrocoll. 23 (2009) 1031-1037.

[44] E.R. Morris, Shear-thinning of "random coil"polysaccharides: Characterisation by two parameters from a simple linear plot, Carbohydr. Polym. 13 (1990) 85-96.

[45] P.B. Fernandes, M.P. Gonçalves, J.L. Doublier, A rheological characterization of kappacarrageenan/galactomannan mixed gels: a comparison of locust bean gum samples, Carbohydr. Polym. 16 (1991) 253-274.

[46] S. Ikeda, K. Nishinari, On solid-like rheological behaviors of globular protein solutions, Food Hydrocoll. 15 (2001) 401-406.

[47] A.I. Rodriguez-Hernandez, S. Durand, C. Garnier, A. Tecante, J.L. Doublier, Rheology-structure properties of gellan systems: evidence of network formation at low gellan concentrations, Food Hydrocoll. 17 (2003) 621-628.

[48] E. Miyoshi, T. Takaya, K. Nishinari, Gel-sol transition in gellan gum solutions. II. DSC studies on the effects of salts, Food Hydrocoll. 8 (1994) 529-542.

[49] C.T. Andrade, E.G. Azero, L. Luciano, M.P. Gonçalves, Rheological properties of mixtures of Kcarrageenan from Hypnea musciformis and galactomannan from Cassia javanica, Int. J. Biol. Macromol. 27 (2000) 349-353.

[50] I.S. Chronakis, J. Borgström, L. Piculell, Conformation and association of K-carrageenan in the presence of locust bean gum in mixed Nal/Csl solutions from rheology and cryo-TEM, Int. J. Biol. Macromol. 25 (1999) 317-328.

[51] M. Yoshimura, T. Takaya, K. Nishinari, Rheological studies on mixtures of corn starch and konjac- 
glucomannan, Carbohydr. Polym. 35 (1998) 71-79.

[52] Y.-H. Chang, S.-T. Lim, B. Yoo, Effect of sucrose on the rheological properties of corn starch, Korean J. Food Sci. Technol. 33 (2001) 700-705.

[53] W. Kulicke, D. Eidam, F. Kath, M. Kix, A.H. Kull, Hydrocolloids and Rheology: Regulation of Visco-elastic Characteristics of Waxy Rice Starch in Mixtures with Galactomannans, Starch-Stärke. 48 (1996) 105114.

[54] J. Korus, L. Juszczak, M. Witczak, B. Achremowicz, Influence of selected hydrocolloids on triticale starch rheological properties, Int. J. Food Sci. Technol. 39 (2004) 641-652.

[55] M. Maskan, F. Göğüş, Effect of sugar on the rheological properties of sunflower oil-water emulsions, J. Food Eng. 43 (2000) 173-177.

[56] S.B. Ross-Murphy, Biophysical Methods in Food Research (Critical Reports on Applied Chemistry), (1984).

[57] J.D. Ferry, Viscoelastic properties of polymers, 3rd edn John Wiley\& Sons, (1980).

[58] D. Khondkar, R.F. Tester, N. Hudson, J. Karkalas, J. Morrow, Rheological behaviour of uncross-linked and cross-linked gelatinised waxy maize starch with pectin gels, Food Hydrocoll. 21 (2007) 1296-1301.

[59] J. Trčková, J. Štetina, J. Kánský, Influence of protein concentration on rheological properties of carrageenan gels in milk, Int. Dairy J. 14 (2004) 337-343.

[60] M. Djabourov, J. Leblond, P. Papon, Gelation of aqueous gelatin solutions. I. Structural investigation, J. Phys. 49 (1988) 319-332.

[61] R. Lapasin, S. Pricl, Rheology, in: Rheol. Ind. Polysaccharides Theory Appl., Springer, 1995: pp. 162-249.

[62] M. Bohdanecky, J. Kovar, Viscosity of polymer solutions, Elsevier Scientific Pub. Co., 1982. 


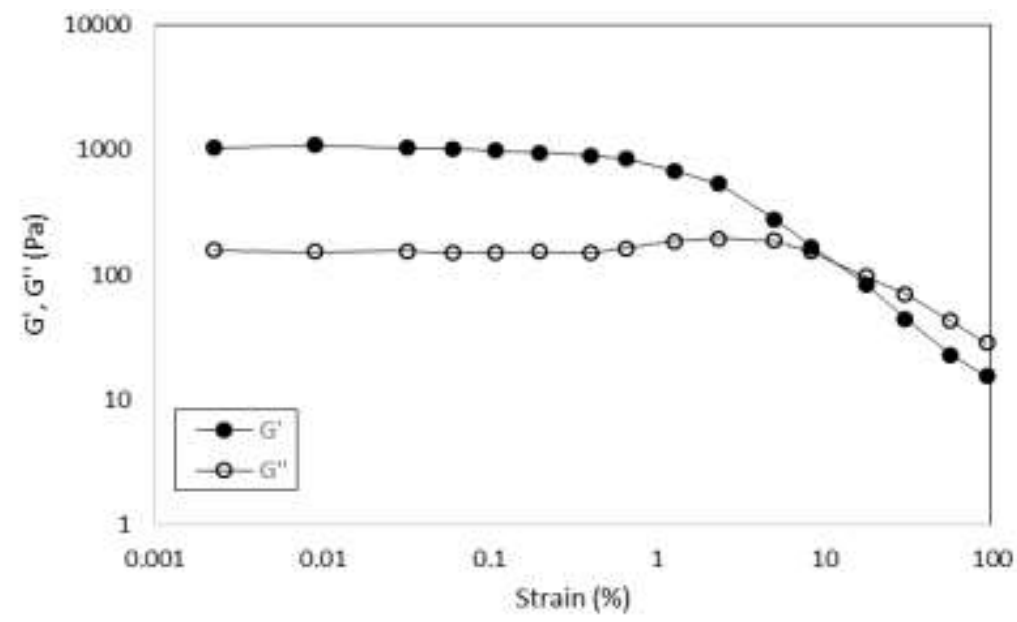

Fig. 1. Strain sweep dependency of storage modulus $\left(\mathrm{G}^{\prime}\right)$ and loss modulus $\left(\mathrm{G}^{\prime \prime}\right)$ for PLSM $(2 \%)$ at $25^{\circ} \mathrm{C}$ (frequency: $1 \mathrm{~Hz}$ ).

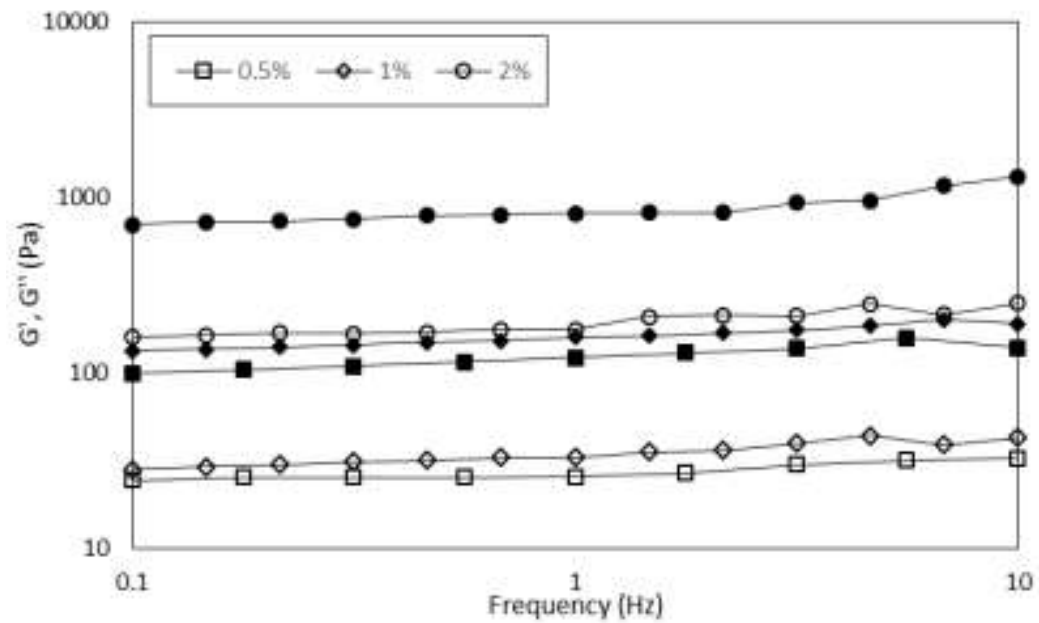

Fig.2. Effect of PLSM concentration on storage modulus (closed symbols) and loss modulus (open symbols) as functions of frequency at $25^{\circ} \mathrm{C}$. 


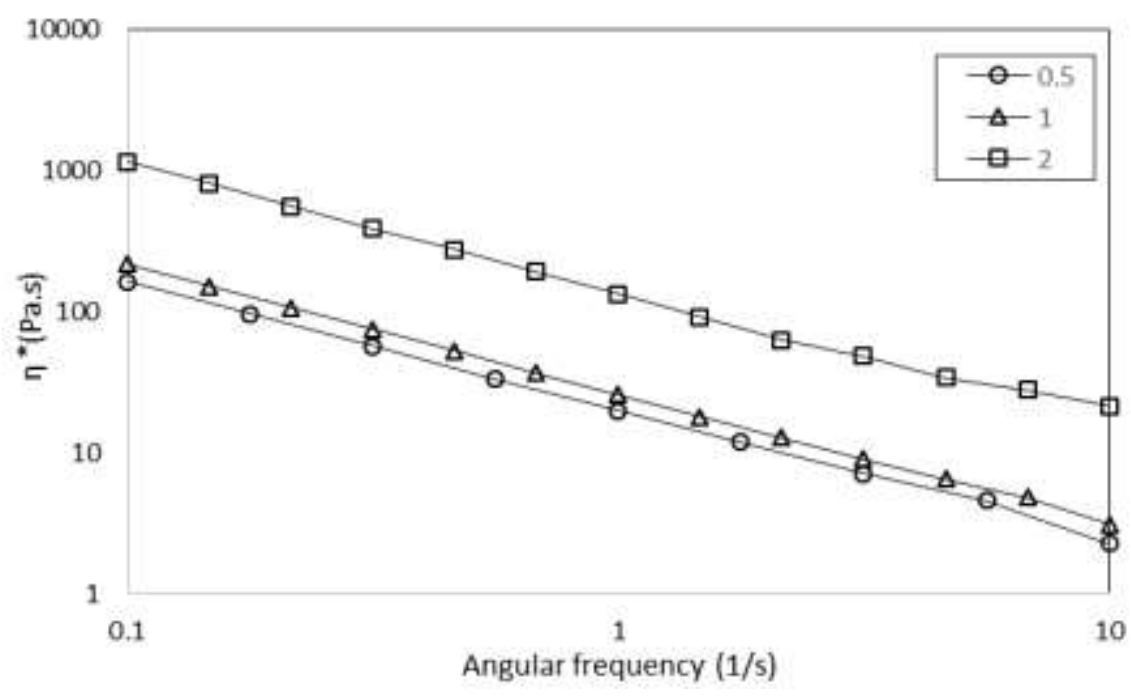

Fig.3. The effect of frequency on complex viscosity $(\eta *)$ of PLSM at different concentrations at $25{ }^{\circ} \mathrm{C}$.
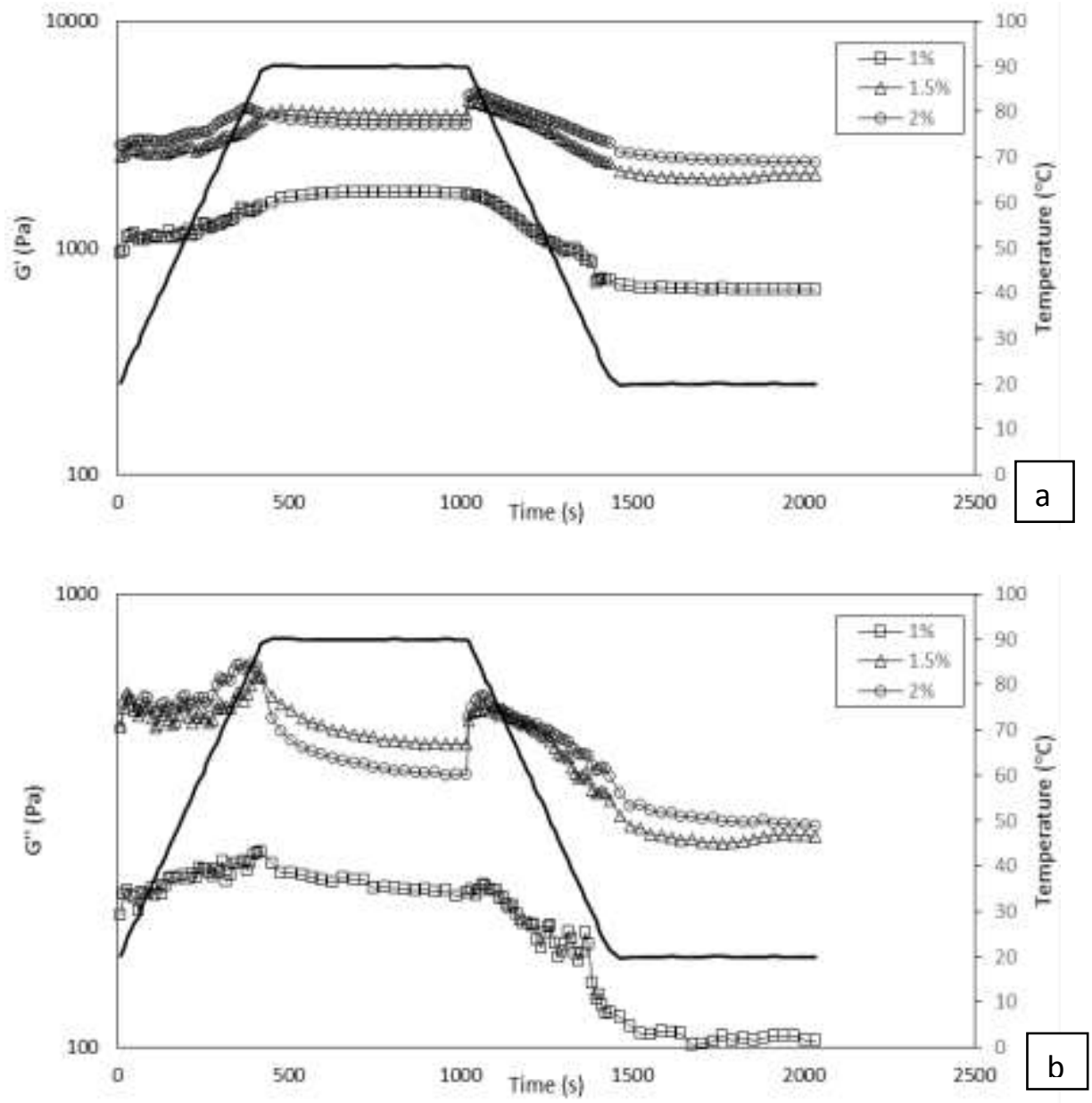
Fig. 4. Storage (a) and loss modulus (b) for different PLSM concentrations during heating cooling at the rate of $10{ }^{\circ} \mathrm{C} / \mathrm{min}$

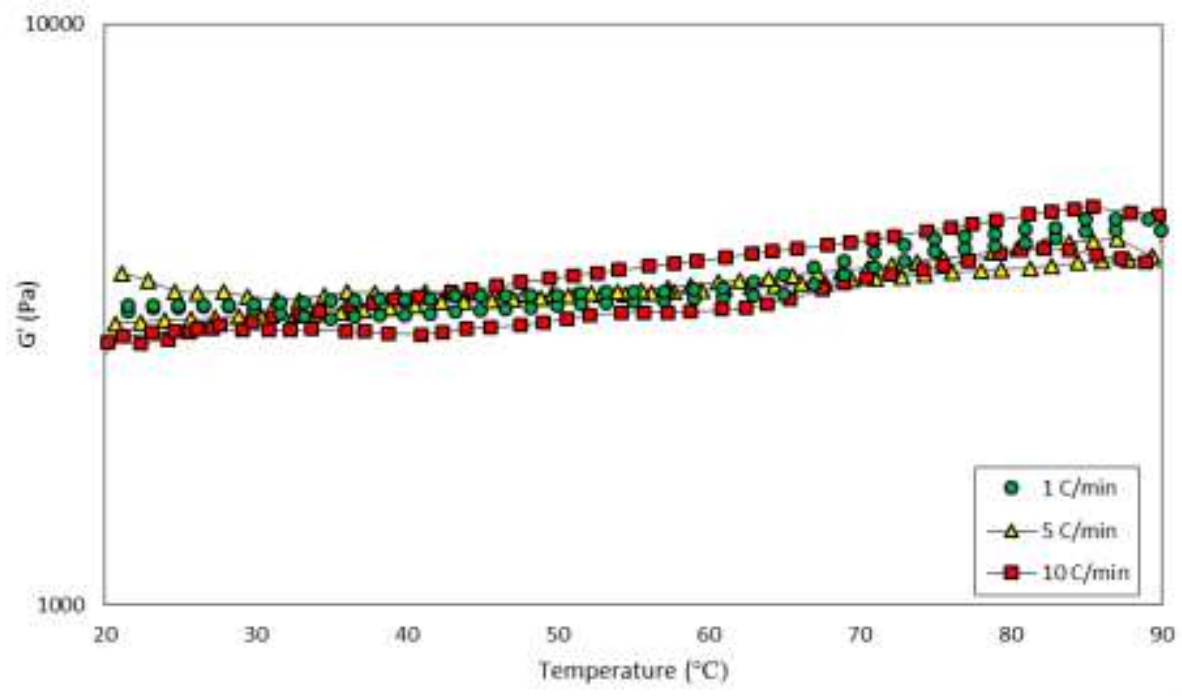

Fig. 5. Variation of storage modulus at different heating cooling rate of $1{ }^{\circ} \mathrm{C} / \mathrm{min}, 5{ }^{\circ} \mathrm{C} / \mathrm{min}$ and $10{ }^{\circ} \mathrm{C} / \mathrm{min}$ at $2 \%$ PLSM concentrations. 
Table1. Chemical composition of PLSM

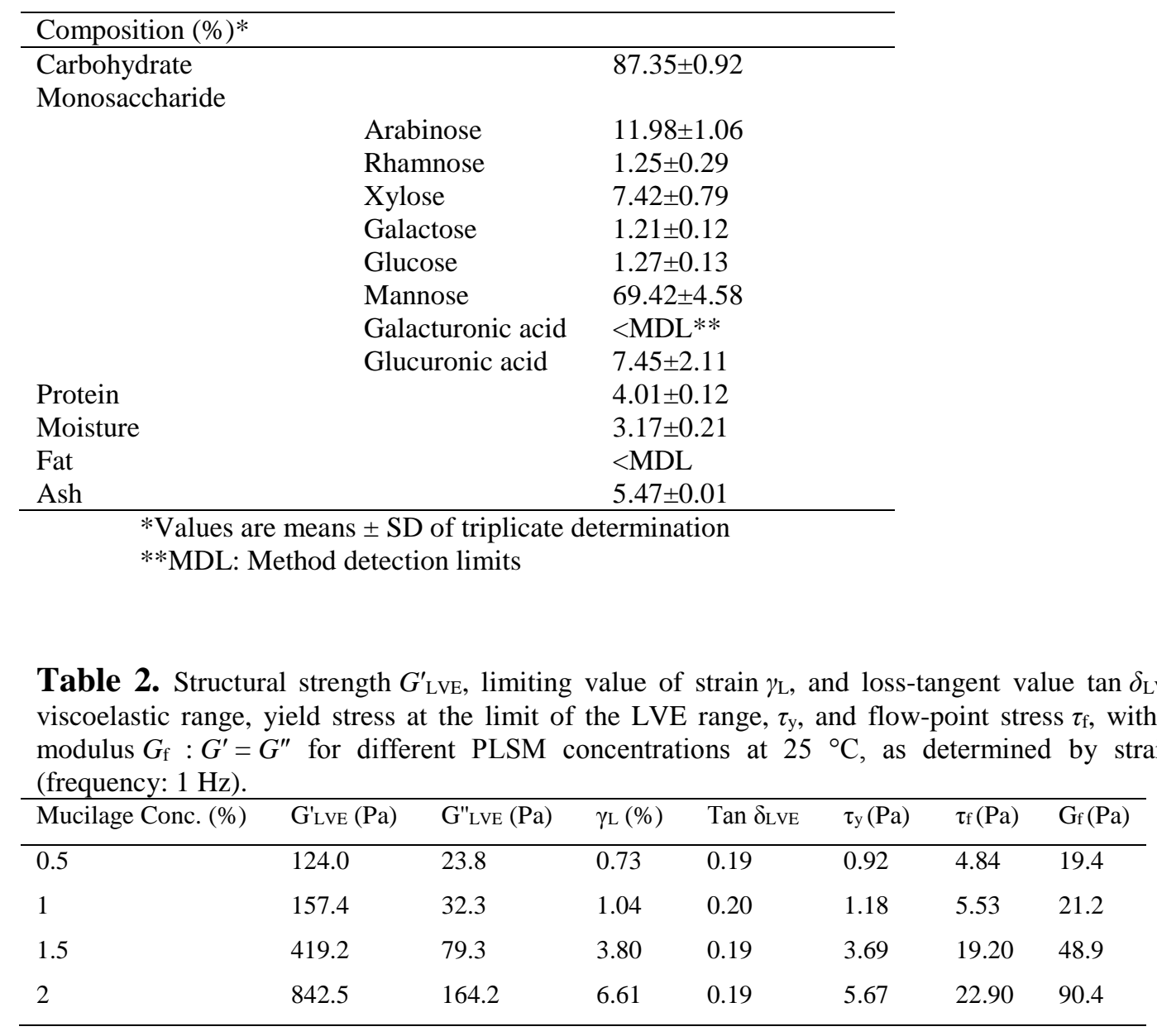

Table.3. Power-law parameters for the storage modulus at $25^{\circ} \mathrm{C}$.

\begin{tabular}{llll}
\hline Mucilage Conc. (\%) & $b$ & $a$ & $\mathrm{R}^{2}$ \\
\hline 0.5 & 0.10 & 122.7 & 0.90 \\
1 & 0.09 & 160.5 & 0.97 \\
1.5 & 0.09 & 429.5 & 0.83 \\
2 & 0.08 & 859.1 & 0.91 \\
\hline
\end{tabular}

